\title{
Retrospective Analysis of Malaria Cases in a Potentially High Endemic Area of Morogoro Rural District, Eastern Tanzania
}

This article was published in the following Dove Press journal: Research and Reports in Tropical Medicine

Joseph N Aikambe ${ }^{1,2}$

Ladslaus L Mnyone ${ }^{2,3}$

'Department of Microbiology, Parasitology and Biotechnology, College of Veterinary Medicine and Biomedical Sciences, Sokoine University of Agriculture, Morogoro, Tanzania; ${ }^{2}$ Pest Management Centre, Sokoine University of Agriculture, Morogoro, Tanzania; ${ }^{3}$ School of Public Health, Faculty of Health Sciences, University of the Witwatersrand, Johannesburg, South Africa
Correspondence: Ladslaus L Mnyone Email llaurent@sua.ac.tz
Background: Malaria is increasingly characterized by appreciable fine-scale variability in ecology and topography, and it is likely that we are missing some salient foci with unprecedented malaria transmission intensity in different parts of Tanzania. Therefore, efforts aimed at identifying area-specific malaria situation and intervening are needed to preserve the realized health gains and achieve elimination. Mkuyuni and Kiroka, adjacent wards within Morogoro Rural District, are purported to form one of such foci.

Patients and Methods: A retrospective study was conducted to determine six-year (2014-2019) malaria prevalence rates based on outpatients and laboratory registers obtained from two health facilities, one per ward, carrying out diagnosis of malaria either through microscopy or malaria rapid diagnostic test (mRDT). These data were checked for completeness before carrying out statistical analysis.

Results: Overall, 35,386 (46.19\%) out of 76,604 patients were positive for malaria. The average proportion of malaria cases was significantly higher in Mkuyuni $(51.23 \%$; $=19,438)$ than Kiroka $(41.21 \% ; \mathrm{n}=15,938)(\mathrm{P}<0.001)$. Females were more affected than males $(\mathrm{P}$ $<0.001)$; , and irrespective of the sex, most malaria cases were recorded in children $<5$ years of age $(\mathrm{P}<0.001)$ except at Mkuyuni. Malaria was recorded virtually all year round; however, the highest proportion of cases was recorded in April and July ( $\mathrm{P}<0.001)$.

Conclusion: This study revealed high malaria endemicity in Mkuyuni and Kiroka, with prevalence rate as high as $60.98 \%$, which is far higher than the overall national average prevalence of $9 \%$. More studies are needed in these and other putatively high endemic foci in Tanzania in order to inform the future course of action in disease surveillance and control. Keywords: malaria, retrospective analysis, high endemic, Mkuyuni and Kiroka wards

\section{Introduction}

Like many other countries, Tanzania has reduced malaria burden by $>50 \%$ over the last decade. ${ }^{1}$ This has been achieved primarily through improved access and use of vector control interventions, diagnostics and treatment. Yet, the current disease burden is still unacceptably high; with an overall prevalence of around $9 \%$ in mainland Tanzania. ${ }^{2}$ People living in resource poor and marginalized areas suffer most; much so the under-five children and pregnant women. These groups are severely affected because they lack acquired and/or have suppressed immunity, respectively. $^{3}$

Well-targeted efforts that embrace area-specific situations, at least in high disease endemic foci, are needed to preserve the realized health gains and advance 
towards elimination. This is because malaria is increasingly characterized by temporal variability that bestows evolving and new challenges to malaria control programs. ${ }^{4}$ Morogoro region, eastern Tanzania is a typical reflection of such a phenomenon because of its appreciable fine-scale variability in ecology and topography. Therefore, it is likely that we are missing salient foci with unprecedented malaria transmission intensity. Kiroka and Mkuyuni, adjacent wards within Morogoro Rural District, are purported to form kind of such foci. Health workers in these areas assert that they receive many cases of severe malaria (Pers. comm.). To preliminarily confirm such assertion and guide the future course of research and action, we analyzed recorded data of malaria cases at the catchment health centres from 2014 to 2019 . Retrospective records provide an excellent resource for estimating areaor region-specific disease burden, thus informing prioritization and/or improvement of surveillance and control strategies. Through this study we obtained useful insights on (i) characteristics of patients (age, sex); (ii) variation of malaria cases with sex and age; (iii) months with high malaria cases and (iv) trend of malaria cases over the years.

\section{Patients and Methods}

\section{Study Area}

The retrospective malaria cases data were obtained from Kiroka (latitude $6.8316^{\circ}$ south and longitude $37.7889^{\circ}$ east) and Mkuyuni (latitude $6.57^{\circ}$ south and longitude $37.48^{\circ}$ east) (Figure 1). These wards are next to each other and are part of Morogoro Rural District, Eastern Tanzania. Kiroka covers $212 \mathrm{~km}^{2}$ with a population of approximately 21,853 people. $^{5}$ Mkuyuni covers $97.4 \mathrm{~km}^{2}$ with a population of approximately 17,935 people. $^{5}$ Agriculture is the main economic activity, and the main crops include rice, maize, banana and coconut. The long rain season runs from March to August and the short season runs from September to mid-December. The dry season runs from January to end of February. Mkuyuni is mountainous and adjacent to several natural forests, thus at times it experiences orographic rainfall. The landscape is bestowed with temporal, semi-permanent and permanent mosquito breeding habitats, particularly in and around the agricultural fields. Despite the asserted malaria transmission risk and intensity, these areas are understudied, if at all.

\section{Study Design}

The retrospective study was conducted to determine sixyear (2014-2019) malaria prevalence based on outpatients and laboratory registers.

\section{Collection of Malaria Cases Data}

The six-year data on malaria cases were obtained from Mkuyuni and Kiroka health centres from 2014 to 2019. We used two health centers, one in each ward. These were the only health centres where malaria diagnosis with either microscopy and/or malaria diagnostic test (mRDT) is done. We only considered malaria cases data which were diagnosed with either microscopy or mRDT. The required sets of information were extracted from patients' register books, and these included reporting date, sex, age and lab results. These data were checked for completeness before being analyzed; and this was done with close assistance from the laboratory personnel in the two health centres. We found a negligible number of incomplete records; and these were excluded from the analysis. Personal information of individual patients was excluded from the final dataset.

\section{Statistical Analysis}

The data set was firstly aggregated by wards, years, age and sex. Based on the age, the data were grouped into two age categories, $<5$ years and $>5$ years. A simple linear regression model in $\mathrm{R}$ Statistical Software was used to determine how the number of malaria cases varied with years, season, age and sex. Data are also presented with appropriate Tables and Figures.

\section{Results \\ Demographic Characteristics}

A total of 76, 604 patients, 12,767 per year, were screened for malaria at Kiroka $(\mathrm{n}=38,698,50.52 \%)$ and Mkuyuni $(\mathrm{n}=37,906,49.48 \%)$ over 6-year period (2014-2019). Of these, 36,952 were $\leq 5$ years of age $($ Kiroka $=17,844$, Mkuyuni $=19,108)$ and 39,652were $>5$ years of age $($ Kiroka $=20,854$, Mkuyuni $=18,798)$. There were 45,767 females $($ Kiroka $=22,587$, Mkuyuni $=23,180)$ and 30,837 males $($ Kiroka $=16,111$, Mkuyuni $=14,726)$.

\section{Malaria Cases}

In both wards altogether, $35,386(46.19 \%)$ out of 76,604 patients were positive for malaria. Despite the fluctuation in malaria cases across years and study areas, there was 


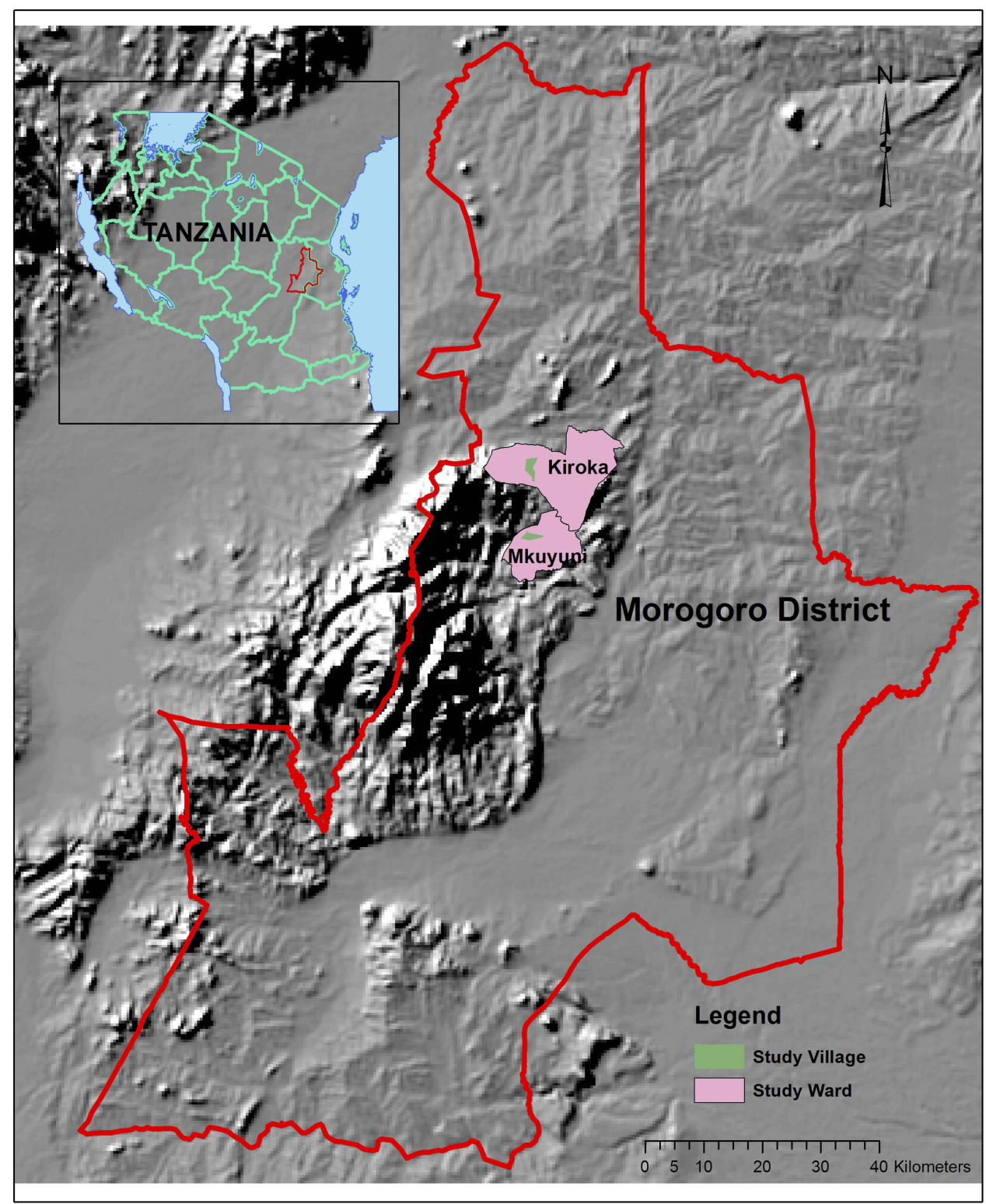

Figure I A map showing wards where the present study was conducted: Mkuyuni and Kiroka wards, Morogoro Rural District, Eastern Tanzania.

a general increase in the disease prevalence rates from 2017 to 2019 (Tables 1 and 2). The highest prevalence rates (up to 60.98\%) were recorded in 2018 and 2019 (Tables 1 and 2). The overall proportion of malaria cases in females was higher than in males $(\mathrm{P}<0.001$, Tables 1 and 2); and most of the cases in both sex were recorded in children below 5 years of age $(\mathrm{P}<0.001)$; except at Mkuyuni, where there was no variation between age groups (Table 1). Malaria was recorded almost all year round; however, the highest proportion of cases for both wards was recorded in April and July $(\mathrm{P}<0.001)$. The average proportion of malaria cases was higher in
Mkuyuni $(51.23 \%$; $\mathrm{n}=19,438)$ than Kiroka $(41.21 \%$; $\mathrm{n}=$ 15,938) $(\mathrm{P}<0.001)$.

\section{Discussion}

This study was done retrospectively using malaria confirmed hospital malaria data collected over a six-year period from 2014 to 2019; with the aim of providing an immediate and readily available resource for estimating area-specific malaria incidences. Based on this retrospective analysis, we have putatively affirmed the assertion that Kiroka and Mkuyuni wards are among the local areas in the Morogoro region that still experience 
Table I Malaria Prevalence Distributed According to Sex and Age at Mkuyuni from 2014 to 2019

\begin{tabular}{|c|c|c|c|c|c|}
\hline Year & & Sexs & Screened & $\begin{array}{l}\text { Malaria } \\
\text { +ve }\end{array}$ & $\begin{array}{l}\text { Prevalence (\%) } \\
(95 \% \mathrm{Cl})\end{array}$ \\
\hline \multirow[t]{5}{*}{2014} & \multirow[t]{2}{*}{ Sex } & Male & 508 & 341 & $67.13(63.04-71.21)$ \\
\hline & & Female & 879 & 486 & $55.29(52.00-58.58)$ \\
\hline & \multirow[t]{2}{*}{ Age } & $\begin{array}{l}<5 \\
\text { years }\end{array}$ & 582 & 379 & $65.12(62.61-67.63)$ \\
\hline & & $\begin{array}{l}>5 \\
\text { years }\end{array}$ & 805 & 448 & $55.65(53.04-58.27)$ \\
\hline & & Overall & 1387 & 827 & $59.63(57.04-62.21)$ \\
\hline \multirow[t]{5}{*}{2015} & \multirow[t]{2}{*}{ Sex } & Male & 991 & 353 & $35.62(32.64-38.60)$ \\
\hline & & Female & 1512 & 528 & $34.92(32.52-37.32)$ \\
\hline & \multirow[t]{2}{*}{ Age } & $\begin{array}{l}<5 \\
\text { years }\end{array}$ & 1193 & 411 & $34.45(32.59-36.31)$ \\
\hline & & $\begin{array}{l}>5 \\
\text { years }\end{array}$ & 1310 & 470 & $35.88(34.00-37.76)$ \\
\hline & & Overall & 2503 & 881 & $35.20(33.33-37.07)$ \\
\hline \multirow[t]{5}{*}{2016} & \multirow[t]{2}{*}{ Sex } & Male & 1389 & 514 & $37.01(34.47-39.54)$ \\
\hline & & Female & 1902 & 664 & $34.91(32.77-37.05)$ \\
\hline & \multirow[t]{2}{*}{ Age } & $\begin{array}{l}<5 \\
\text { years }\end{array}$ & 1560 & 652 & $41.79(40.11-43.48)$ \\
\hline & & $\begin{array}{l}>5 \\
\text { years }\end{array}$ & 1731 & 526 & $30.39(28.82-31.96)$ \\
\hline & & Overall & 3291 & 1178 & $35.79(34.16-37.43)$ \\
\hline \multirow[t]{5}{*}{2017} & \multirow[t]{2}{*}{ Sex } & Male & 3567 & 2102 & $58.93(57.31-60.54)$ \\
\hline & & Female & 5393 & 2847 & $52.79(51.46-54.12)$ \\
\hline & \multirow[t]{2}{*}{ Age } & $\begin{array}{l}<5 \\
\text { years }\end{array}$ & 4768 & 2781 & $58.33(57.31-59.35)$ \\
\hline & & $\begin{array}{l}>5 \\
\text { years }\end{array}$ & 4192 & 2168 & $51.72(50.68-52.75)$ \\
\hline & & Overall & 8960 & 4949 & $55.23(54.20-56.26)$ \\
\hline \multirow[t]{5}{*}{2018} & \multirow[t]{2}{*}{ Sex } & Male & 5174 & 3161 & $61.09(59.77-62.42)$ \\
\hline & & Female & 8331 & 4249 & $51.00(49.93-52.08)$ \\
\hline & \multirow[t]{2}{*}{ Age } & $\begin{array}{l}<5 \\
\text { years }\end{array}$ & 6727 & 4183 & $62.18(61.36-63.00)$ \\
\hline & & $\begin{array}{l}>5 \\
\text { years }\end{array}$ & 6778 & 3227 & $47.61(46.77-48.45)$ \\
\hline & & Overall & 13,505 & 7410 & $54.87(54.03-54.03)$ \\
\hline \multirow[t]{2}{*}{2019} & \multirow[t]{2}{*}{ Sex } & Male & 3097 & 1615 & $52.15(50.39-53.91)$ \\
\hline & & Female & 5163 & 3422 & $66.28(64.99-67.57)$ \\
\hline
\end{tabular}

(Continued)
Table I (Continued).

\begin{tabular}{|l|l|l|l|l|l|}
\hline Year & & Sexs & Screened & $\begin{array}{l}\text { Malaria } \\
+\mathrm{ve}\end{array}$ & $\begin{array}{l}\text { Prevalence (\%) } \\
(95 \% \mathrm{Cl})\end{array}$ \\
\hline \multirow{7}{*}{ Age } & $\begin{array}{l}<5 \\
\text { years }\end{array}$ & 4278 & 2765 & $64.63(63.60-65.66)$ \\
\cline { 3 - 6 } & $\begin{array}{l}>5 \\
\text { years }\end{array}$ & 3982 & 2272 & $57.06(55.99-58.12)$ \\
\cline { 2 - 6 } & Overall & 8260 & 5037 & $60.98(59.93-62.03)$ \\
\hline
\end{tabular}

proportionally high malaria incidences. Over the six-year period, both wards recorded 76,604 patients whose malaria infection status was examined by either microscopy or mRDTs. Nearly half ( $\mathrm{n}=35,386,46.19 \%)$ of these patients were malaria positive. The recorded number of patients might be lower than it should be because self-medication without confirmatory diagnosis is still a common practice in Tanzania. ${ }^{6-12}$ Self-medication in Tanzania and most of the SSA is driven by several factors including distance to health facility, cost of medication and services, shortages of medicines, waiting times for receiving services and attitudes toward patient displayed by health care workers. ${ }^{10,11,13}$ Furthermore, since this study only considered malaria cases confirmed by microscopy or mRDTs, many malaria cases could have been missed during stockouts of reagents and/or mRDTs in the study health facilities. Health workers in the study health centers affirmed to have experienced the stockouts or reagents and/or mRDTs, sometimes for several months.

Despite the fluctuation in malaria cases across the years and study areas, there was a general increase in disease prevalence rates from 2017 to 2019. Overall, the highest malaria prevalence rates (up to 60.98\%) were recorded across the study sites from 2017 to 2019. These prevalence rates were relatively higher than the national average. The average malaria prevalence in mainland Tanzania stands at 9\%. ${ }^{1}$ However, the prevalence varies considerably between and within regions across the country. Notably, malaria prevalence varies from $<1 \%$ in the highlands of Arusha to as high as $41 \%$ along the Lake Victoria shores. ${ }^{1}$ The general increase in the proportion of patients and confirmed malaria cases across the study sites from 2017 -2019 is unlikely due to increased malaria transmissions, but rather due to improved community awareness and availability of diagnostics mainly mRDTs. Such an association has been emphasized elsewhere in SSA. ${ }^{14}$ Before 
Table 2 Malaria Prevalence Distributed According to Sex and Age at Kiroka Ward from 2014 to 2019

\begin{tabular}{|c|c|c|c|c|c|}
\hline Year & & Sex & Screened & $\begin{array}{l}\text { Malaria } \\
\text { +ve }\end{array}$ & $\begin{array}{l}\text { Prevalence }(\%) \\
(95 \% \mathrm{Cl})\end{array}$ \\
\hline \multirow[t]{5}{*}{2014} & \multirow[t]{2}{*}{ Sex } & Male & 2174 & 675 & $31.05(29.10-32.99)$ \\
\hline & & Female & 2930 & 713 & $24.33(22.78-25.89)$ \\
\hline & \multirow[t]{2}{*}{ Age } & $\begin{array}{l}<5 \\
\text { years }\end{array}$ & 2373 & 651 & $27.43(26.2 \mathrm{I}-28.66)$ \\
\hline & & $\begin{array}{l}>5 \\
\text { years }\end{array}$ & 2731 & 737 & $26.99(25.77-28.20)$ \\
\hline & & Overall & 5104 & 1388 & $27.19(24.85-29.54)$ \\
\hline \multirow[t]{5}{*}{2015} & \multirow[t]{2}{*}{ Sex } & Male & 3032 & 1532 & $50.53(48.75-52.31)$ \\
\hline & & Female & 4655 & 1868 & $40.13(38.72-41.54$ \\
\hline & \multirow[t]{3}{*}{ Age } & $\begin{array}{l}<5 \\
\text { years }\end{array}$ & 3326 & 1634 & $49.13(48.01-50.25)$ \\
\hline & & $\begin{array}{l}>5 \\
\text { years }\end{array}$ & 4361 & 1766 & $40.50(39.40-41.59)$ \\
\hline & & Overall & 7687 & 3400 & $44.23(42.56-45.90)$ \\
\hline \multirow[t]{5}{*}{2016} & \multirow[t]{2}{*}{ Sex } & Male & 2183 & 684 & $31.33(29.39-33.28)$ \\
\hline & & Female & 3005 & 818 & $27.22(25.63-28.81)$ \\
\hline & \multirow[t]{2}{*}{ Age } & $\begin{array}{l}<5 \\
\text { years }\end{array}$ & 2406 & 714 & $29.68(28.43-30.92)$ \\
\hline & & $\begin{array}{l}>5 \\
\text { years }\end{array}$ & 2782 & 788 & $28.32(27.10-29.55)$ \\
\hline & & Overall & 5188 & 1502 & $28.95(26.66-31.25)$ \\
\hline \multirow[t]{5}{*}{2017} & \multirow[t]{2}{*}{ Sex } & Male & 1847 & 816 & $44.18(41.91-46.44)$ \\
\hline & & Female & 2298 & 985 & $42.86(40.84-44.89)$ \\
\hline & \multirow[t]{3}{*}{ Age } & $\begin{array}{l}<5 \\
\text { years }\end{array}$ & 1897 & 812 & $42.80(41.30-44.31)$ \\
\hline & & $\begin{array}{l}>5 \\
\text { years }\end{array}$ & 2248 & 989 & $43.99(42.48-45.5 I)$ \\
\hline & & Overall & 4145 & 1801 & $43.45(41.16-45.74)$ \\
\hline \multirow[t]{5}{*}{2018} & \multirow[t]{2}{*}{ Sex } & Male & 4223 & 2400 & $56.83(55.34-58.33)$ \\
\hline & & Female & 5868 & 2919 & $49.74(48.47-51.02)$ \\
\hline & \multirow[t]{2}{*}{ Age } & $\begin{array}{l}<5 \\
\text { years }\end{array}$ & 4577 & 2568 & $56.11(55.14-57.07)$ \\
\hline & & $\begin{array}{l}>5 \\
\text { years }\end{array}$ & 5514 & 2751 & $49.89(48.92-50.87)$ \\
\hline & & Overall & $|0,09|$ & 5319 & $52.71(51.37-54.05)$ \\
\hline \multirow[t]{2}{*}{2019} & \multirow[t]{2}{*}{ Sex } & Male & 2652 & 1008 & $38.01(36.16-39.86)$ \\
\hline & & Female & 3831 & 1530 & $39.94(38.39-41.49)$ \\
\hline
\end{tabular}

(Continued)
Table 2 (Continued).

\begin{tabular}{|l|l|l|l|l|l|}
\hline Year & & Sex & Screened & $\begin{array}{l}\text { Malaria } \\
+ \text { ve }\end{array}$ & $\begin{array}{l}\text { Prevalence (\%) } \\
(\mathbf{9 5 \%} \text { Cl) }\end{array}$ \\
\hline \multirow{3}{*}{ Age } & $\begin{array}{l}<5 \\
\text { years }\end{array}$ & 3265 & 1281 & $39.23(38.05-40.42)$ \\
\cline { 2 - 6 } & $\begin{array}{l}>5 \\
\text { years }\end{array}$ & 3218 & 1257 & $39.06(37.87-40.25)$ \\
\cline { 2 - 5 } & Overall & 6483 & 2538 & $39.15(37.25-41.05)$ \\
\hline
\end{tabular}

the introduction and improved access to diagnostics like mRDTs, particularly in infrastructure and resourcechallenged rural settings; malaria diagnosis was done overwhelmingly based on clinical presentation. As such, many people felt contempt that they could diagnose and treat themselves.

Moreover, other factors which could have been responsible to the fluctuation of malaria cases observed over the six-year period of this study include ecologic and environmental factors, host and vector behavioral characteristics, population immunity to malaria, efficiency and/or coverage of mosquito control interventions as well as the economic status of reference communities. ${ }^{15}$ Our follow-up studies in the present sites will explore the status and dynamics of these and other relevant factors.

Males across all age groups were more affected compared to females; and this corroborates with the findings of many other studies carried out in Tanzania and elsewhere. ${ }^{4,15-20}$ The study done in selected areas of Mvomero district, Tanzania revealed 16\% higher odds of having malaria in males relative to females. This could be attributed to the lifestyle and occupation of males. Males are usually involved in agricultural, day labor and hunting in environments that are suitable for mosquito breeding. Besides, most males spend much time outdoors and/or go to bed late compared to females, thus increasing their exposure to mosquito bites.

All age groups were affected by malaria. However, children below 5 years of age were disproportionately affected. This is consistent with many other studies. ${ }^{1,19,21}$ Globally, children under 5 years of age suffer the greatest malaria burden, as they are yet to develop immunity to malaria. ${ }^{22-24}$ Indeed, this group accounts for approximately $61 \%$ of all malaria-related deaths worldwide. ${ }^{25}$ However, studies are emphasizing the shift of malaria incidences to older age categories. ${ }^{26-28}$ The study done 
in Gwanda district, Zimbabwe showed that malaria incidences are higher $(95 \%)$ in the $>5$ age category. ${ }^{31}$ A similar shift has been reported in Tanzania, ${ }^{29-31}$ Botswana, ${ }^{32}$ Ghana $^{33}$ and Gambia. ${ }^{34}$ Results of the present study showed no variation of malaria cases between the younger and older age categories at Mkuyuni ward. Presumably, this could be an indication of the shift of malaria to older age categories.

This study depicted malaria cases virtually all year round, with peak in April and July. These months coincide with the beginning and end of long rain season which runs from March to August each year. Many parts of the Morogoro region and Tanzania in general experience high malaria prevalence rates more or less during these months.

Although the prevalence of malaria in both wards is equally concerning, the highest proportion of malaria cases were recorded in Mkuyuni. This variation could be explained by a higher proportion of semi-permanent and permanent breeding sites at Mkuyuni relative to Kiroka. Mkuyuni has a relatively higher proportion of watersheds. Studies conducted in Mvomero district, Morogoro region associated watersheds with high malaria prevalence. ${ }^{4}$ High watersheds ensure temperature and humidity conditions that are conducive to the distribution and survival of malaria vectors. ${ }^{4}$ Moreover, Mkuyuni is far from Urban Morogoro relative to Kiroka and as such majority of its population depends on smallholder farms hence they are somehow economically disadvantaged. As such, their use of control interventions such as LLINs could be comparatively low. Unfortunately, this proposition was beyond the scope of this study; thus, it remains rather speculative; therefore, our future studies will aim to confirm it among other factors. The coverage of LLINs in certain rural areas of the Morogoro region, presumably Mkuyuni and Kiroka wards, is regrettably still low; , and even worse, majority of the people who own LLINs do not deploy them appropriately. $^{35}$

Like any other retrospective study relying on existing records, this study had some limitations. There was a possibility of missing data and/or wrong entry in some of the records. Health facility data has a potential for underreporting malaria cases as a considerable proportion of people may not have presented at the health facilities due to different factors. Besides, a considerable proportion of malaria cases must have been missed during stockouts of reagents and/or mRDTs. Equally important, several other factors may have confounded the observed results, for example, impact of malaria control activities as well as host- and mosquito-related ecological and environmental factors.

\section{Conclusion}

Although the overall morbidity and mortality of malaria have decreased in Tanzania, some high endemic foci, like Mkuyuni and Kiroka, may still be available in different parts of the country. The present study revealed malaria prevalence rate of up to $60.98 \%$, which is far higher than the national average. Therefore, further research to understand and/or estimate malaria transmission risk and incidences in putatively high endemic foci are desirable in view of informing rational and well-targeted surveillance and control efforts.

\section{Data Sharing Statement}

The datasets generated and analysed during this study are not publicly available but can be obtained from the corresponding author on reasonable request.

\section{Ethics and Consent Statement}

Ethical approval was granted by the Ethics Review Committee of Sokoine University of Agriculture (SUA), Morogoro, Tanzania. The malaria cases data were provided upon request to the Health Officers in charge. All patient data complied with applicable data protection regulations.

\section{Acknowledgments}

We would like to extend our sincere thanks to Mr. Awadhi Juma and Mrs Sayuni, the Health Officers in charge at Mkuyuni and Kiroka, respectively, for providing malaria cases data. We are also indebted to Mr. Godfrey Katus for assistance on data analysis. Equally important, we thank the community leaders of Mkuyuni and Kiroka for permitting us to carry out this study in the area.

\section{Author Contributions}

Both authors made substantial contributions to the conception and design, data collection or analysis and interpretation of data; took part in drafting the article and revising it; and gave final approval of the version to be published and agree to be accountable to all aspects of the work.

\section{Funding}

This research was part of MSc studies research for Mr. Joseph N Aikambe and was self-sponsored. 


\section{Disclosure}

The authors declare that they have no competing interests.

\section{References}

1. Tanzania's Ministry of Health, Gender, Elderly and Children. Tanzania Demographic and Health Survey and Malaria Indicator Survey (TDHS-MIS) 2015-2016; 2016.

2. Tanzania Ministry of Health, Ministry of Health Zanzibar, (NBS) NB of S. Tanzania Malaria Indicator Survey (TMIS): Key Indicators 2017. Dodoma; 2018.

3. Bwire GM, Mwambete KD. Immunological perspectives of sub-Saharan populations under prophylaxis against malaria. JIIDT. 2019. doi:10.31579/2637-8876/00

4. Rumisha SF, Shayo EH, Mboera LEG. Spatio-temporal prevalence of malaria and anaemia in relation to agro-ecosystems in Mvomero district, Tanzania. Malar J. 2019;18:228. doi:10.1186/s12936-019-2859-y

5. National Bureau of Statistics (NBS). The 2012 Population and Housing Census, Population Distribution by Age and Sex (Volume II). Dar Es Salaam, Tanzania; 2013.

6. Goodman C, Patrick Kachur S, Abdulla S, et al. Retail supply of malariarelated drugs in rural Tanzania: risks and opportunities. Trop Med Int Health. 2004;9(6):655-663. doi:10.1111/j.1365-3156.2004.01245.x

7. Hetzel MW, Alba S, Fankhauser M, et al. Malaria risk and access to prevention and treatment in the paddies of the Kilombero Valley, Tanzania. Malar J. 2008;7:7. doi:10.1186/1475-2875-7-7

8. Ringsted FM, Massawe IS, Lemnge MM, Bygbjerg IC. Saleability of anti-malarials in private drug shops in Muheza, Tanzania: a baseline study in an era of assumed artemisinin combination therapy (ACT). Malar J. 2011;10:238. doi:10.1186/1475-2875-10-238

9. Rutta E, Kibassa B, McKinnon B, et al. Increasing access to subsidized artemisinin-based combination therapy through accredited drug dispensing outlets in Tanzania. Health Res Policy Syst. 2011;9:22. doi:10.1186/1478-4505-9-22

10. Chipwaza B, Mugasa JP, Mayumana I, Amuri M, Makungu C, Gwakisa PS. Self-medication with anti-malarials is a common practice in rural communities of Kilosa district in Tanzania despite the reported decline of malaria. Malar J. 2014;13:252. doi:10.1186/14752875-13-252

11. Metta E, Haisma H, Kessy F, et al. "We have become doctors for ourselves": motives for malaria self-care among adults in southeastern Tanzania. Malar J. 2014;13(1):249. doi:10.1186/1475-2875-13-249

12. Kajeguka DC, Moses EA. Self-medication practices and predictors for self-medication with antibiotics and antimalarials among community in Mbeya City, Tanzania. TJHR. 2017;19. doi:10.4314/thrb.v19i4.6

13. Lowassa A, Mazigo HD, Mahande AM, et al. Social economic factors and malaria transmission in Lower Moshi, Northern Tanzania. Parasite Vectors. 2012;5(1):129. doi:10.1186/1756-3305-5-129

14. Lechthaler F, Matthys B, Lechthaler-Felber G, et al. Trends in reported malaria cases and the effects of malaria control in the Democratic Republic of the Congo. PLoS One. 2019;14(7): e0219853. doi:10.1371/journal.pone.0219853

15. Alemu A, Muluye D, Mihret M, Adugna M, Gebeyaw M. Ten year trend analysis of malaria prevalence in Kola Diba, North Gondar, North west Ethiopia. Parasite Vectors. 2012;5(1):173. doi:10.1186/ 1756-3305-5-173

16. Karunamoorthi K, Bekele M. Changes in malaria indices in an Ethiopian health centre: a five year retrospective analysis. Health Scope. 2012;1(3):118-126. doi:10.5812/jhs.7076

17. Tesfaye S, Belyhun Y, Teklu T, Mengesha T, Petros B. Malaria prevalence pattern observed in the highland fringe of Butajira, Southern Ethiopia: a longitudinal study from parasitological and entomological survey. Malar J. 2011;10:153. doi:10.1186/14752875-10-153
18. Afoakwah C, Deng X, Onur I. Malaria infection among children under-five: the use of large-scale interventions in Ghana. $B M C$ Public Health. 2018;18:536. doi:10.1186/s12889-018-5428-3

19. Sena LD, Deressa WA, Ali AA. Analysis of trend of malaria prevalence in south-west Ethiopia: a retrospective comparative study. Malar J. 2014;13:188. doi:10.1186/1475-2875-13-188

20. Tesfaye K, Yohannes M, Bayisa S. Trend analysis of malaria prevalence in Raya Azebo district, Northern Ethiopia: a retrospective study. BMC Res Notes. 2018;11(1):900. doi:10.1186/s13104-0184003-4

21. Yeshiwondim AK, Gopal S, Tekle AH, Dengel DO, Patel H. Spatial analysis of malaria incidence at the village level in areas with unstable transmission in Ethiopia. Int $J$ Health Geogr. 2009;8:5. doi:10.1186/1476-072X-8-5

22. Chan JA, Howell KB, Reiling L, et al. Targets of antibodies against Plasmodium falciparum-infected erythrocytes in malaria immunity. J Clin Invest. 2012;122(8):3227-3238. doi:10.1172/JCI62182

23. Rono J, Osier FH, Olsson D, et al. Breadth of anti-merozoite antibody responses is associated with the genetic diversity of asymptomatic Plasmodium falciparum infections and protection against clinical malaria. Clin Infect Dis. 2013;579(10):1409-1416. doi:10.1093/cid/cit556

24. Roberts D, Matthews G. Risk factors of malaria in children under the age of five years old in Uganda. Malar J. 2016;15:246. doi:10.1186/ s12936-016-1290-x

25. WHO. World Malaria Report 2017. Geneva: World Health Organization; 2018.

26. Schellenberg D, Menendez C, Aponte J, et al. The changing epidemiology of malaria in Ifakara Town, southern Tanzania. Trop Med Int Health. 2004;9:68-76. doi:10.1046/j.13653156.2003.01161.x

27. Reyburn H, Mbatia R, Drakeley C, et al. Association of transmission intensity and age with clinical manifestations and case fatality of severe Plasmodium falciparum malaria. JAMA. 2005;293 (12):1461-1470. doi:10.1001/jama.293.12.1461

28. Chimbari MJ. Trans-Boundary Diagnostic Assessment. Maun: Okavango Research Institute, University of Botswana; 2009.

29. Gunda R, Chimbari MJ, Shamu S, Sartorius B, Mukaratirwa S. Malaria incidence trends and their association with climatic variables in Rural Gwanda, Zimbabwe, 2005-2015. Malar J. 2017;16(1):393. doi:10.1186/s12936-017-2036-0

30. Ishengoma D, Segeja MD, Alifrangis M, Lemnge MM, BygbjergIb C. Declining burden of malaria over two decades in a rural community of Muheza district, north-eastern Tanzania. Malar J. 2013;12:388. doi:10.1186/1475-2875-12-338

31. Winskill P, Rowland M, Mtove G, Malima RC, Kirby MJ. Malaria risk factors in north-east Tanzania. Malar J. 2011;20:98. doi:10.1186/ 1475-2875-10-98

32. Chirebvu E, Chimbari MJ, Ngwenya BN, Sartorius B. Clinical malaria trans-mission trends and its association with climatic variables in Tubu Village, Botswana: a retrospective analysis. PLoS One. 2016;11:e0139843. doi:10.1371/journal.pone.0139843

33. Okafor FU, Oko-Ose JN. Prevalence of malaria infections among children aged six months to eleven years (6 months-11 years) in a tertiary institution in Benin City, Nigeria. Global Adv Res J Med Sci. 2012;1:273-279.

34. Ceesay SJ, Casals-Pascual C, Erskine J, et al. Changes in malaria indices between 1999 and 2007 in the Gambia: a retrospective analysis. Lancet. 2008;372(9649):1545-1554. doi:10.1016/S01406736(08)61654-2

35. Solomon T, Loha E, Deressa W, Gari T, Overgaard HJ, Lindtjørn B. Low use of long-lasting insecticidal nets for malaria prevention in south-central Ethiopia: a community-based cohort study. PLoS One. 2019;14:e0210578. doi:10.1371/journal.pone.0210578 


\section{Publish your work in this journal}

Research and Reports in Tropical Medicine is an international, peerreviewed, open access journal publishing original research, case reports, editorials, reviews and commentaries on all areas of tropical medicine, including: Diseases and medicine in tropical regions; Entomology; Epidemiology; Health economics issues; Infectious disease; Laboratory science and new technology in tropical medicine;

Submit your manuscript here: http://www.dovepress.com/research-and-reports-in-tropical-medicine-journal
Parasitology; Public health medicine/health care policy in tropical regions; and Microbiology. The manuscript management system is completely online and includes a very quick and fair peer-review system. Visit http://www.dovepress.com/testimonials.php to read real quotes from published authors. 